\title{
Wavelet maxima curves of surface latent heat flux anomalies associated with Indian earthquakes
}

\author{
G. Cervone ${ }^{1}$, R. P. Singh ${ }^{1,2}$, M. Kafatos ${ }^{1}$, and C. Yu ${ }^{1}$ \\ ${ }^{1}$ Center for Earth Observing and Space Research, School of Computational Sciences, George Mason University, Fairfax, VA \\ 22039, USA \\ ${ }^{2}$ Department of Civil Engineering, Indian Institute of Technology, Kanpur 208 016, India
}

Received: 6 May 2004 - Revised: 21 October 2004 - Accepted: 6 December 2004 - Published: 17 January 2005

\begin{abstract}
Wavelet maxima curves of surface latent heat flux (SLHF) have been recently used to provide early warning information about coastal earthquakes. The present paper reports further validations of the spatial and temporal analysis of wavelet maxima curves associated with earthquakes occurred in different parts of the Indian sub-continent. Prominent anomalies that exhibit spatial and temporal continuity are found in case of coastal earthquakes, while no anomaly is detected in case of intraplate earthquakes. The precursory SLHF anomalies are found up to 2 weeks prior to the main earthquake event, with an extent area of up to $600 \mathrm{~km}$.
\end{abstract}

\section{Introduction}

Significant changes in land, oceanic and atmospheric parameters have been observed prior to large earthquakes using remote sensing data (Singh et al., 2001; Tramutoli et al., 2001; Tronin et al., 2002; Dey and Singh, 2003; Ouzonov and Freund, 2004; Cervone et al., 2004; Liu et al., 2004; Maekawa and Hayakawa, 2004; Pulinets and Boyarchuk, 2004). These changes suggest the existence of possible interaction between the lithosphere and the atmosphere, and have opened up new possibilities to the use of satellite-based observations to study earthquakes precursors.

Cervone et al. (2004) have introduced a new data mining methodology based on wavelet transformations and statistical analysis to detect precursory signals associated with earthquakes. This methodology was validated on two large earthquakes occurred in Greece using SLHF data. Prominent anomalies were detected about two weeks prior to both events, suggesting the possibility of developing an early warning system for impending earthquakes. Dey and Singh (2003) and Singh et al. (2004) have recently shown in the

Correspondence to: R. P. Singh

(rsingh3@gmu.edu) case of coastal earthquakes the consistent occurrence of anomalous SLHF peaks a few days prior to the main earthquake event. They have concluded that the continuous measurements of SLHF can provide early warning information about an impending coastal earthquake. The magnitudes of the SLHF peaks are found to be variable, while SLHF tends to be higher over oceans and lower over land. The origin of the anomalous SLHF is likely to be related with the increase of surface temperature in the epicentral region which is associated with the build up of stress and movements along the faults. It is believed that the temperature increases prior to an earthquake (Qiang, 1997). For example, changes in temperature up to $5 \mathrm{~K}$ for the Gujarat earthquake of 26 January 2001 has been mapped using Infrared (IR) wavelength observations by the Moderate Resolution Imaging Spectroradiometer (MODIS) sensor (http://amesnews.arc.nasa.gov/releases/ 2002/02images/quakes/earthquakes.html) and is likely due to frictional mechanism along the fault or due to movements of the fluids at depth (Ouzonov and Freund, 2004). Due to the heat conduction, the sea surface temperature increases which in turn is likely responsible for increasing the ocean evaporation giving rise to anomalous SLHF prior to the main earthquake events (Dey and Singh, 2003).

In this paper, the general methodology discussed by Cervone et al. (2004) has been applied to five large earthquakes which occurred in different locations of the Indian subcontinent. The present paper further validates the methodology on earthquakes occurring in different geographical region, and to characterize the extent and the geometrical shape of the anomalies in order to discriminate from similar anomalies due to other atmospheric or oceanic phenomena. The earthquakes considered occurred in four different regions of India, which are characterized by different types of seismic events. Statistical $t$ tests are used to determine the statistical significance of the detected anomalies. 


\section{Data and Methodology}

The SLHF data used in the present study cover the period from 1 January 1998 to 28 March 2004 for the region bounded by latitudes $33 \mathrm{~N}$ to $45 \mathrm{~N}$ and longitudes $14 \mathrm{E}$ to $28 \mathrm{E}$. The SLHF data have been downloaded from the website of the Scientific Computing Division of the National Center for Atmospheric Research (NCAR) (http://ingrid. ldeo.columbia.edu/SOURCES/NOAA/NCEP-NCAR/). The plate boundary data have been downloaded from http:// www-geology.ucdavis.edu/GEL102/demets.html, and consist of the best fitting Euler vectors, closure fitting Euler vectors and the global model NUVEL-1 to describe geologically current plate motions between 12 assumed rigid plates. The details of this dataset are described by DeMets et al. (1990). The methodology employed uses wavelet transformations as data mining tools by computing the wavelet maxima that propagate from coarser to finer scales (Cervone et al., 2004). Those maxima are used to identify strong anomalies in the data; however only those anomalies that show continuity in both time and space are assumed as possible precursors for earthquakes. Time continuity means that the detected anomalies occur at the same time or with a short delay with respect to each other, while space continuity means that the detected anomalies are distributed in space according to a precise geometry conforming to the relevant geological settings of the region. Details of the SLHF data used in the present study and methodology are discussed in detail by Cervone et al. (2004).

The wavelet analysis is also paired with statistics to determine the significance of the singularities found. The first step consists in computing the 30 days average and its standard deviation using several years of prior data. In the present work, five years of prior data are used due to the unreliability of data with longer temporal coverage. For each year prior to the earthquake, a 365-days long time series is transformed into 12 data points, each being the average of 30 days, except for the last that is the average of either 35 or 36 days. The average and standard deviation are computed using the 12 data points for all previous years, and are later expanded to the original size of 365 days, by assigning the value of each data point to a sequence of 30 consecutive points, except the last that has 35. As a result the average and standard deviation are two step functions with a length of 365 . A spline interpolation is used to smooth both the computed average and the standard deviation.

The following $t$ test is performed on the singularities detected by the wavelet transformation to determine the statistical significance of the peaks. The $t$ test is commonly used in statistics to determine if the mean of the population and the mean of the sample are statistically different Miller et al. (1997).

Let

$\bar{X}=\frac{\sum X_{i}}{n}$ where $\bar{X}$ is the unbiased estimator of the population mean, $n$ is the number of points used in the computation of the average and standard deviation (in the present work, $n=30 * 5=150$ because we use the 30 days average for five years of data) and $X_{i}$ is the ith point of the time series for the year of the earthquake, and

$S^{2}=\frac{\sum\left(X_{i}-\bar{X}\right)^{2}}{n-1}$

where $S^{2}$ is the unbiased estimator of the population variance, $X_{i}$ is the ith point of the time series for the year of the earthquake, and $\bar{X}$ is the mean previously computed.

Based on the Central Limit Theorem

$\bar{X} \sim N\left(\mu_{i}, \frac{\sigma_{i}^{2}}{n}\right)$

where $N$ represents the normal distribution, with mean $\mu_{i}$, estimated by $\bar{X}$, and variance $\sigma_{i}^{2}$ estimated by $S^{2}$. In other words, we expect the sample mean to asymptotically come from a normal distribution.

A new mean is created

$\mu_{i}^{\prime}=\mu_{i}+b \frac{\sigma_{i}}{\sqrt{n}}$

where $\mu_{i}$ and $\sigma$ are the mean and the standard deviation of the normal distribution, and $b$ is a constant used to adjust the allowed level of oscillations in the data. In the experiments $b$ is always set equal to 1 . Hence

$\mu_{i}^{\prime} \sim N\left(\mu_{i}+b \frac{\sigma_{i}}{\sqrt{n}}, \frac{\sigma_{i}^{2}}{n}\right)$

A new data point $y_{i}$ is tested by comparing $\mu_{i}^{\prime}$ with $y_{i}$, using the two following hypotheses:

$H_{0}: y_{i}=\mu_{i}^{\prime}$

$H_{1}: y_{i}>\mu_{i}^{\prime}$

An hypothesis is accepted or rejected according to the $t$ test

$t=\frac{y_{i}-\mu_{i}^{\prime}}{\frac{\sigma_{i}}{\sqrt{n}}}$

In the present work, the estimate of the test statistics, which is $t$, is computed by

$\hat{t}=\frac{y_{i}-\bar{X}-b \frac{S}{\sqrt{n}}}{\frac{S}{\sqrt{n}}}$

If $\hat{t}$ is greater than a predefined quantile value (at $\alpha 0.05$ significance level, the corresponding quantile is $\hat{t}_{1-\alpha, n}$ or 1.65) then we reject $H_{0}$ and conclude that the data point $y_{i}$ is statistically significant. $1-\alpha$ is used because the methodology is for a one-sided $t$ test. 


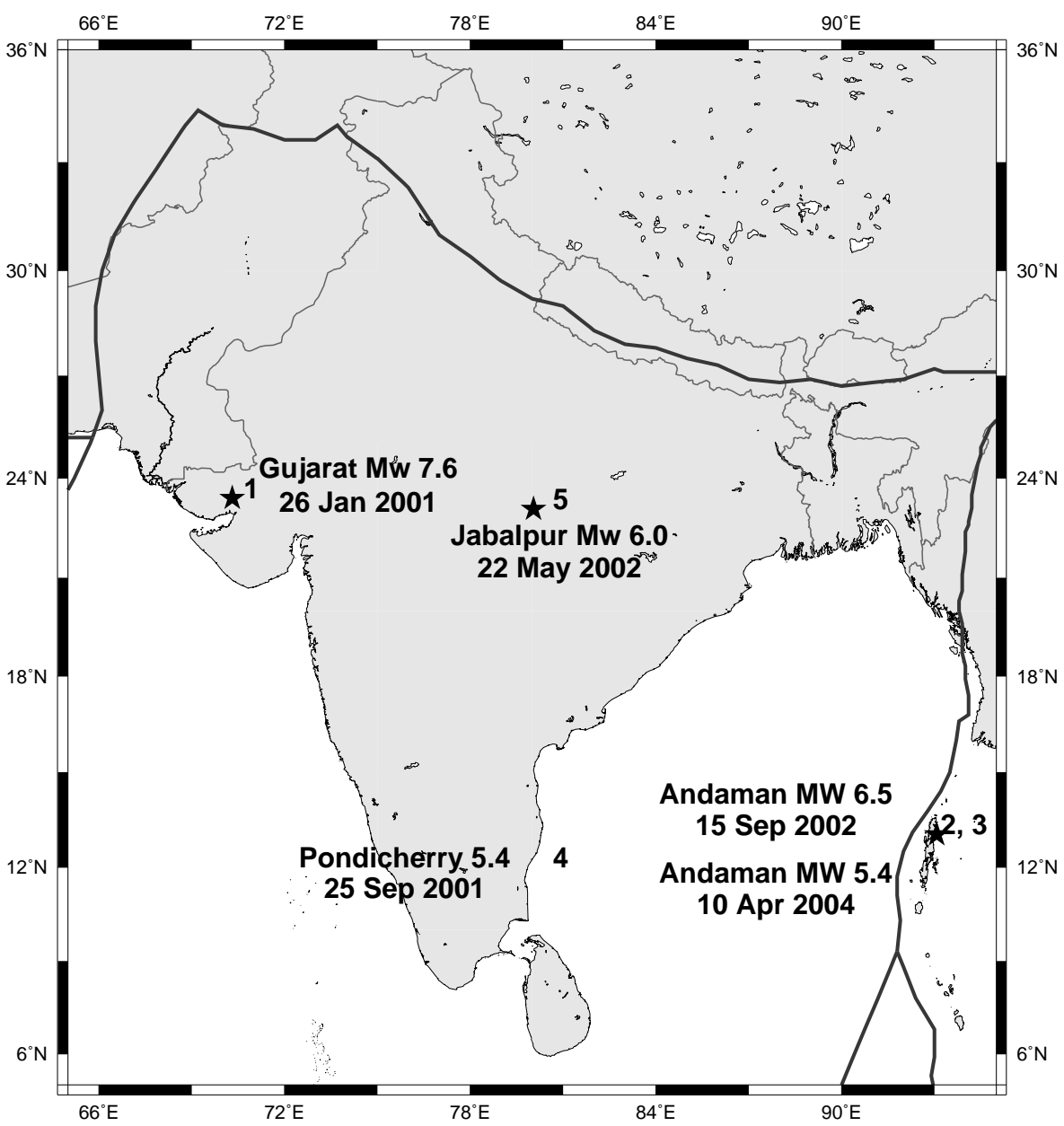

Fig. 1. Map of India indicating the location of the Earthquakes. The epicenters are marked with a star, and annotated with the location, time and magnitude of the earthquake. The plate boundary is also indicated

Table 1. Details of the earthquakes used in the experiments.

\begin{tabular}{ccccc}
\hline Earthquake Event & Date & Location & Focal Depth & Magnitude \\
\hline Gujarat & 26 January 2001 & 23.399 N 70.316 E & $17 \mathrm{~km}$ & 7.6 \\
Andaman 1 & 13 September 2002 & 13.04 N 93.07 E & $21 \mathrm{~km}$ & 6.5 \\
Andaman 2 & 10 April 2004 & 13.04 N 93.25 E & $33 \mathrm{~km}$ & 5.4 \\
Pondicherry & 25 September 2001 & 11.94 N 80.22 E & $19 \mathrm{~km}$ & 5.4 \\
Jabalpur & 22 May 1997 & 23.08 N 80.04 E & $35 \mathrm{~km}$ & 6.0 \\
\hline
\end{tabular}

\section{Results and Discussion}

Detailed analysis has been performed using SLHF data for five earthquakes which occurred in different parts of India, namely Gujarat (1), Andaman (2 and 3), Pondicherry (4), and Jabalpur (5) (Fig. 1). Details of these earthquakes are given in Table 1 .

A 1-D wavelet transformation has been applied on several grids adjacent to the epicentral region. The goal is to identify singularities in the data, defined as abrupt changes in the first derivative of the time-series. The maxima of the wavelet coefficients at different scales have been com- puted by generating maxima curves which propagate from the coarser to the finest scales. All the singularities corresponding to maxima curves which propagate from the finest to a fraction of the total number of scale, are considered to be significant. Such technique has the advantage of effectively filtering out seasonal components, which show primarily at coarser scales (lower frequency), and also high frequency noise which does not propagate through the wavelet coefficients. Additionally, only the anomalies with statistical significance are kept, namely those whose magnitude is above the noise level for the region, computed using five years of prior data. This wavelet transformations is carried out not 
Table 2. Parameters of the numerical real wavelet transformation (RWT) used in the experiments.

\begin{tabular}{cc}
\hline Function & RWT \\
\hline Mother Wavelet & Sombrero \\
Nvoice & 10 \\
Scale & 10 \\
Octave & 2 \\
Propagation Factor & $\frac{1}{2}$ \\
\hline
\end{tabular}

only for the grid comprising the epicenter of the earthquake, but also for several adjacent region. The wavelet analysis has been performed using 365 SLHF data points, corresponding to one year of data. The parameters used in the wavelet analysis are given in Table 2.

The second step is to discriminate anomalies associated with earthquakes from those due to other atmospheric or oceanic phenomena by using the concept of spatial and time continuity. Time continuity means that the detected anomalies occur at the same time or with a short delay of each other, while space continuity means that the detected anomalies are distributed in space according to a precise geometry conforming to the geological settings of the region. Anomalies associated with earthquakes are caused by a large scale event, and thus their extent is not confined only to the epicentral area. Additionally, such anomalies have a peculiar characteristic geometrical shape, which can be used to discriminate from other anomalies. The identifications of anomalies associated with earthquakes is carried out by selecting anomalies with a characteristic geometrical shape and occurring all at the same time or within a short time period (usually 1 or 2 days). The geometrical shape of the anomalies are likely to be related to the geological characteristics of the region, such as continental boundaries or fault lines. The results of the wavelet analysis are given in three parts:

1. The first part shows the time series for the original signal, the 30 days average for the previous five years 1998-2002, and the 1 and 2 standard deviations (sigma) line for the 30 days average. The average has been interpolated using a spline based algorithm to generate a smooth line.

2. The second part is a graphical representation which shows the time when significant wavelet maxima are detected. The color indicates the propagation depth in order to emphasize those maxima which propagate to the finer scales.

3. The third and last part consists of a graphical representation of the wavelet coefficients, and the corresponding maxima lines.

The results of the space and time continuity are shown in Figs. $2 b, 6 b$ and $8 b$. In the figures, the $x$-axis represents time expressed in days, and the y-axis represents the grid of the grid path. The strength of the anomaly is color coded. The parameters used to compute the spatial and temporal continuity are given on top of each figure.

\subsection{Gujarat}

The Gujarat earthquake ( $\mathrm{Mw}=7.6)$, occurred on 26 January, 2001, at 03:16 UTC, and its epicenter was calculated at location $23.399 \mathrm{~N} 70.316 \mathrm{E}$, with a focal depth of $17 \mathrm{~km}$. The earthquake occurred along an approximately east-west trending thrust. This is an intraplate earthquake, since it occurred far away from the continental boundary. Historically, this region is hit by a major earthquake every 100 years. During the period of quiescence, none or very little seismic activity is recorded. In particular, in the 6 months prior to the 2001 earthquake, there was no seismic activity recorded by the global seismic network.

The 26 January, 2001, earthquake is one of the most deadly earthquakes that occurred in the Indian subcontinent. The large magnitude of the event and the lack of safety standards as well as a low level of preparedness of the population caused great losses of lives and properties. Official Indian Government figures reported about 20000 deaths and about 170000 injured. The entire region suffered with great depression causing damages between 1 and 5 billion dollars, and affecting the life of several million people. The general destruction of building caused large amount of dust, which increased the aerosol concentration and affected the local climate (Okada et al., 2004).

The SLHF data are analyzed over several grids shown in Fig. 2a. Each grid is annotated with a unique number on the bottom left, and with the day of when the anomaly was detected, and the offset from the day of the earthquake. The annotation " 23 Jan - 3 ", means that the anomaly was detected on 23 January 2001, which is 3 days prior to the earthquake event. When grids have more than one anomaly, they are listed consecutively in chronological order. This grid path is chosen following the coastline, and it also reflects the locations where thermal anomalies associated with this earthquake have been recently found from MODIS data ${ }^{1}$. The MODIS data has shown an increase up to $5^{0} \mathrm{~K}$ in the surface temperature over the epicentral region prior to the earthquake event (Ouzonov and Freund, 2004). The increase in thermal temperature is found to be associated with the tectonic settings of the region. In fact, one of the crucial parts of this experiment was the selection of the grids in the absence of distinct tectonic features, such as continental boundaries. This region contains very complicated faults rather short in length which, combined with the coarse resolution of the SLHF data, make the selection of the grid path a nontrivial task. In this particular case, the thermal anomalies observed using MODIS are important for the selection of the appropriate grid path.

\footnotetext{
${ }^{1}$ http://amesnews.arc.nasa.gov/releases/2002/02images/quakes/ earthquakes.html
} 


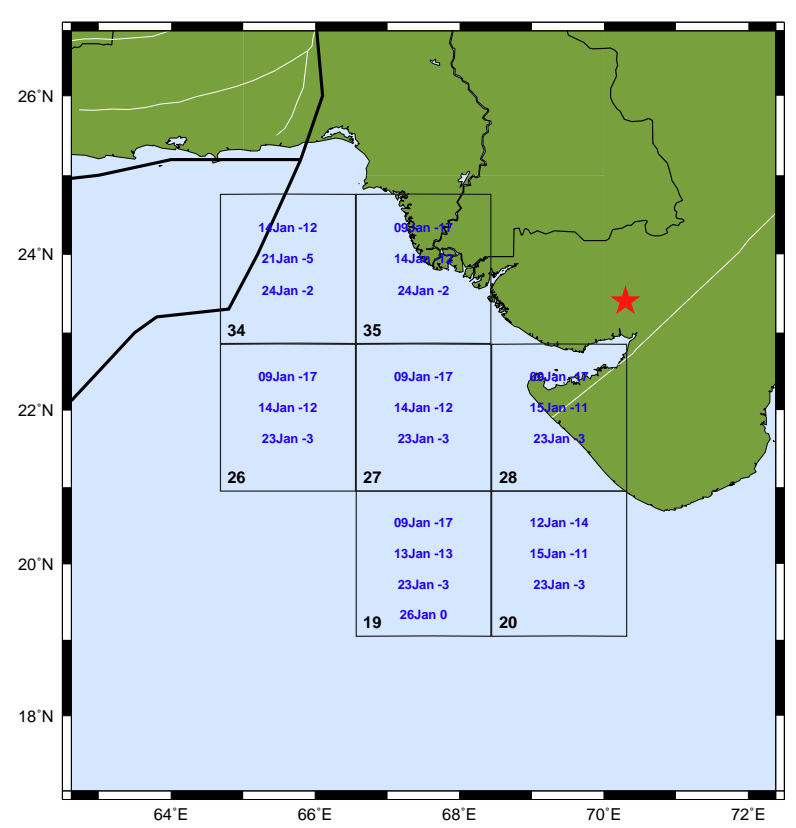

(a) Extent of the SLHF anomalies

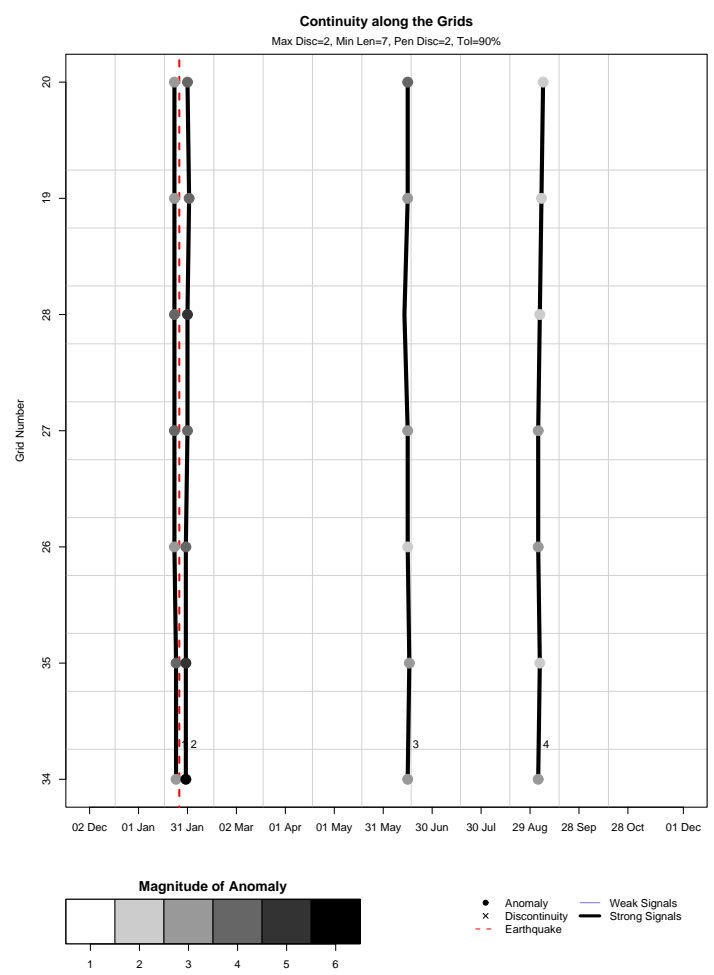

(c) Time and space analysis of SLHF data
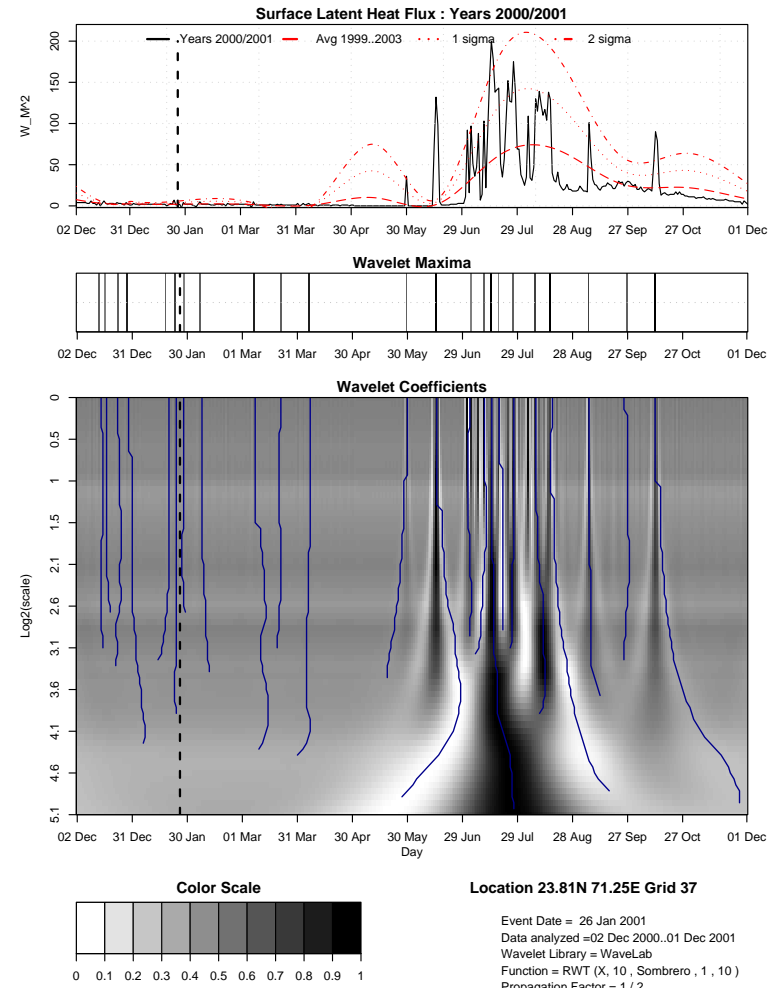

(b) Wavelet analysis using SLHF data
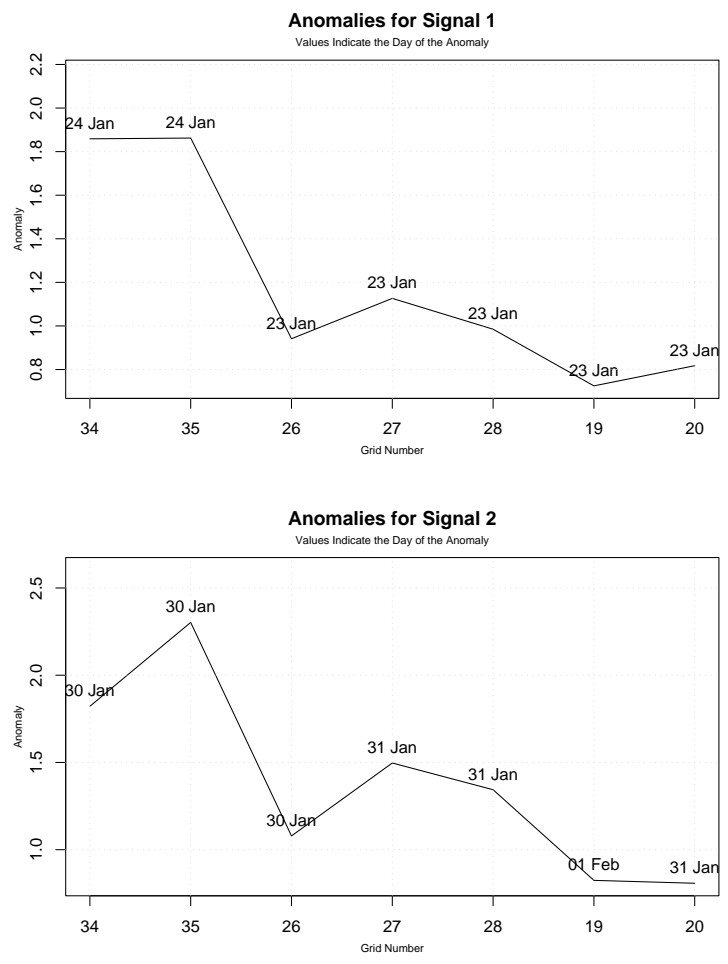

(d) Magnitude of the SLHF anomalies

Fig. 2. Results for the Gujarat earthquake of 26 January 2001. 
SLHF for $23.81 \mathrm{~N} 65.62 \mathrm{E}$ Grid 34

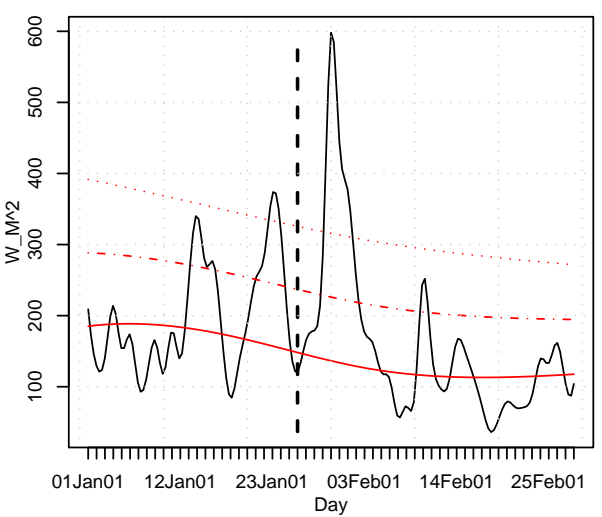

SLHF for 23.81N 67.5E Grid 35

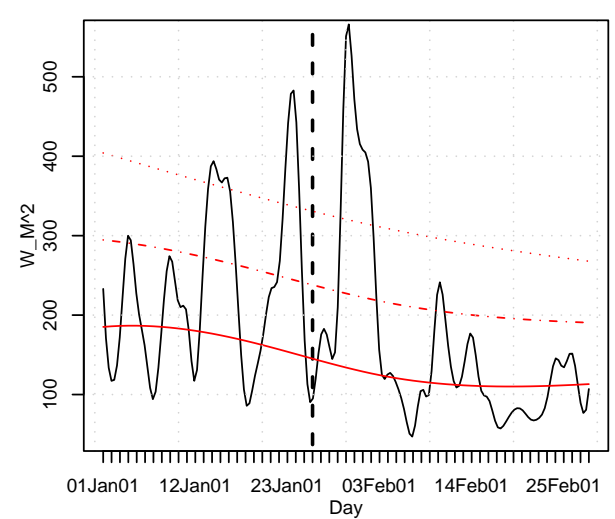

SLHF for 21.9N 65.62E Grid 26

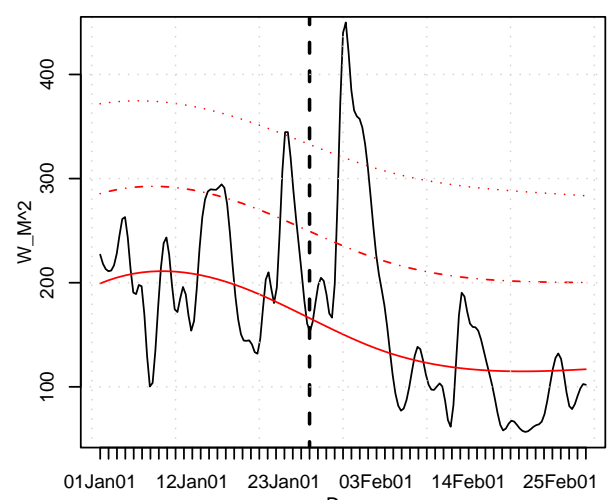

Test for 23.81N 65.62E Grid 34

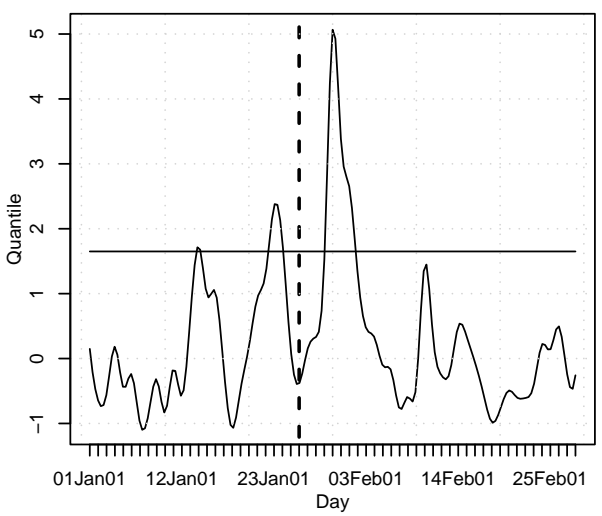

Test for 23.81N 67.5E Grid 35

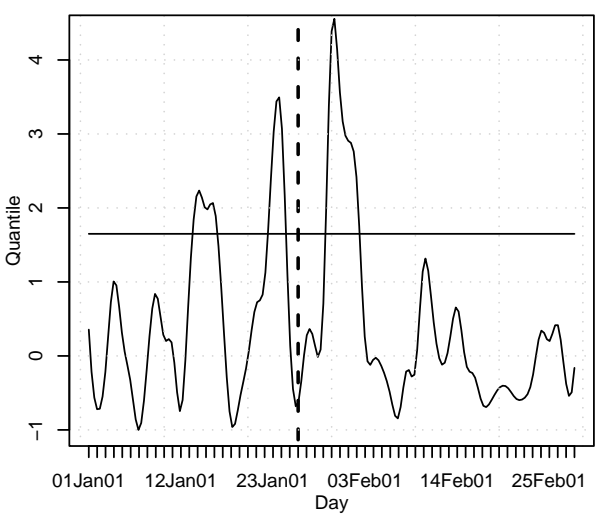

Test for 21.9N 65.62E Grid 26

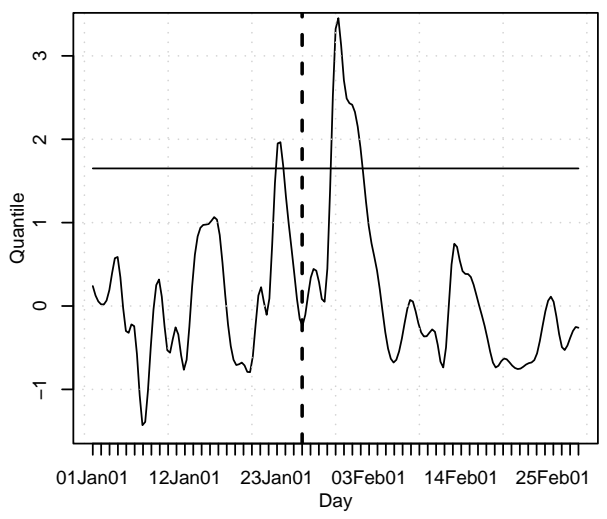

Fig. 3. Statistical test of the SLHF anomalies for the Gujarat earthquake of 26 January 2001.

Figure $2 b$ shows the wavelet transformation for the epicentral region using SLHF data. The earthquake signal is not seen in this figure because the vertical scale is too small due the presence of the monsoon in the summer months. However, the SLHF signal is found to be anomalous 3 days prior and 5 days after the earthquake event, with a magnitude of about 3 times the average for this period of the year. Figure 2 shows the time and space continuity computed using the defined grid path (c) and the magnitudes of the detected anomalies for the signals associated with the earthquake event (d). During a one year period, only four signals are found which follow this precise geometrical path, out of which one occurs about 3 days prior and one about 5 days after the Gujarat earthquake. The grid path was chosen selecting grids over the ocean adjacent to the epicentral region. The highest anomalies occur in grid 35, which is one of the 
SLHF for 21.9N 67.5E Grid 27

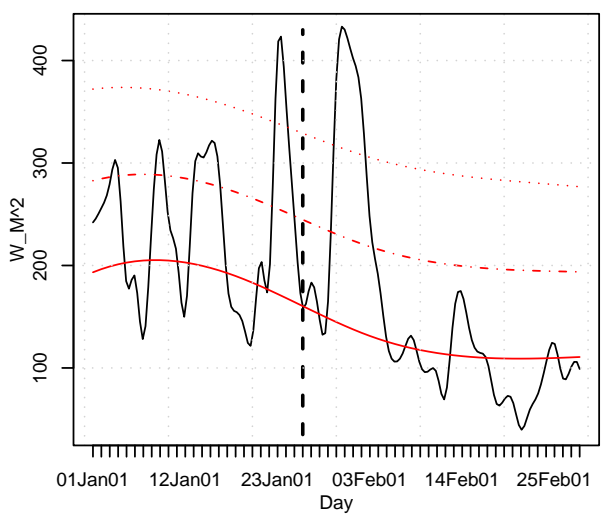

SLHF for 21.9N 69.38E Grid 28

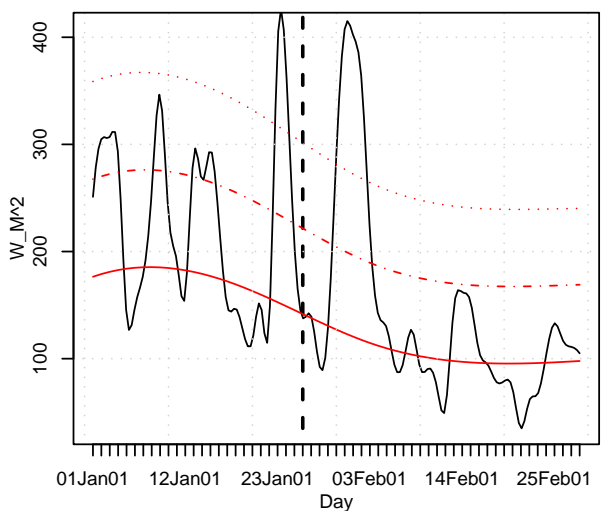

SLHF for 20N 69.38E Grid 20

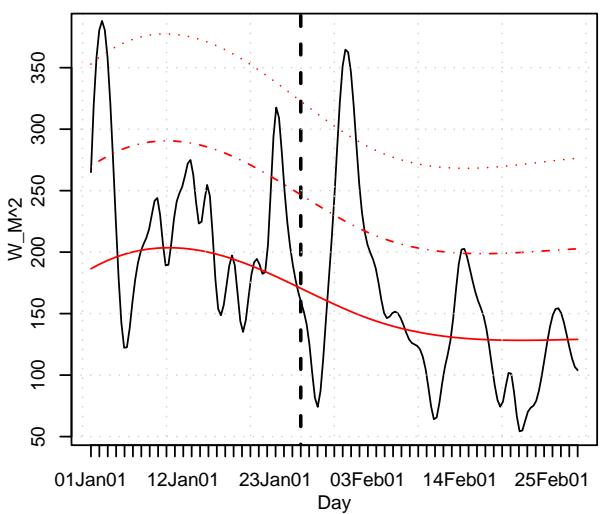

Test for 21.9N 67.5E Grid 27

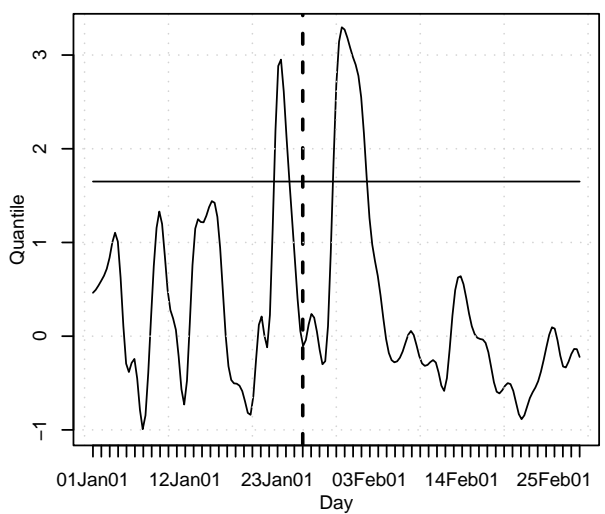

Test for 21.9N 69.38E Grid 28

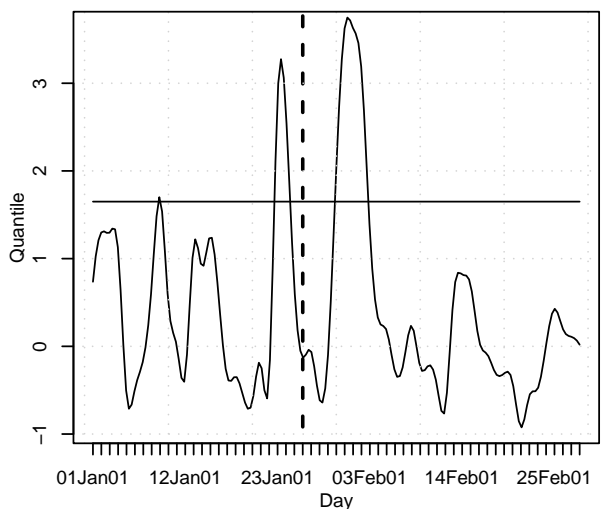

Test for 20N 69.38E Grid 20

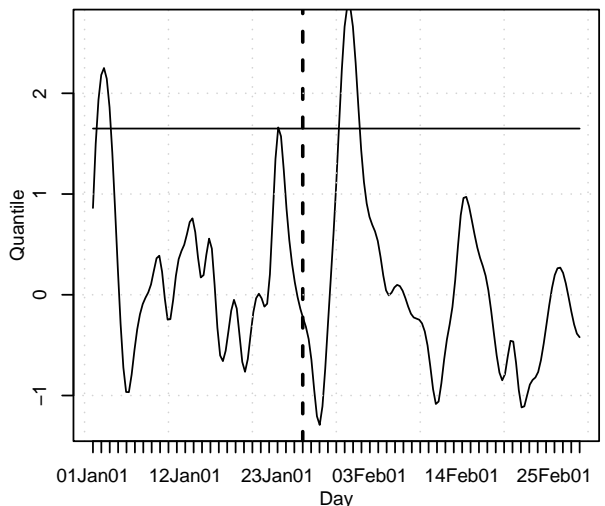

Fig. 4. Statistical test of the SLHF anomalies for the Gujarat earthquake of 26 January 2001.

grids closest to the epicenter. The statistical test described in Sect. 2 was performed to determine which anomalies in the grid path are statistically significant, and the results are presented in Figs. 3 and 4. Each figure is composed of pairs of images lined up horizontally. The left image shows the original signal for the months of January and February 2001, plus the 30 days average, one sigma and two sigmas. The right image shows the normalized signal for the same time period, and the horizontal line indicating the minimum quantile required to pass the test. If a peak is higher than the horizontal line, it is considered to be statistically significant. All grids used in the study show significant peaks 3 days before and 5 days after the earthquake.

Grids over the land were not chosen because their SLHF value for this time of the year is too small, around $10 \mathrm{~W} / \mathrm{m}^{2}$. Figure 5 shows a sequence of the detected SLHF anomalies. 


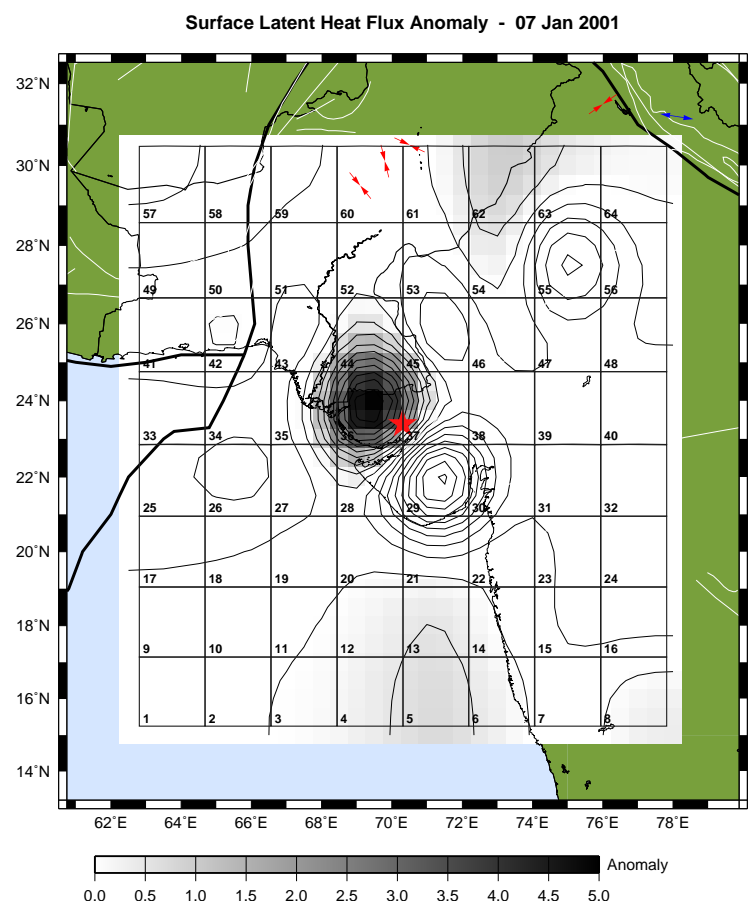

(a) SLHF anomaly for January 72001

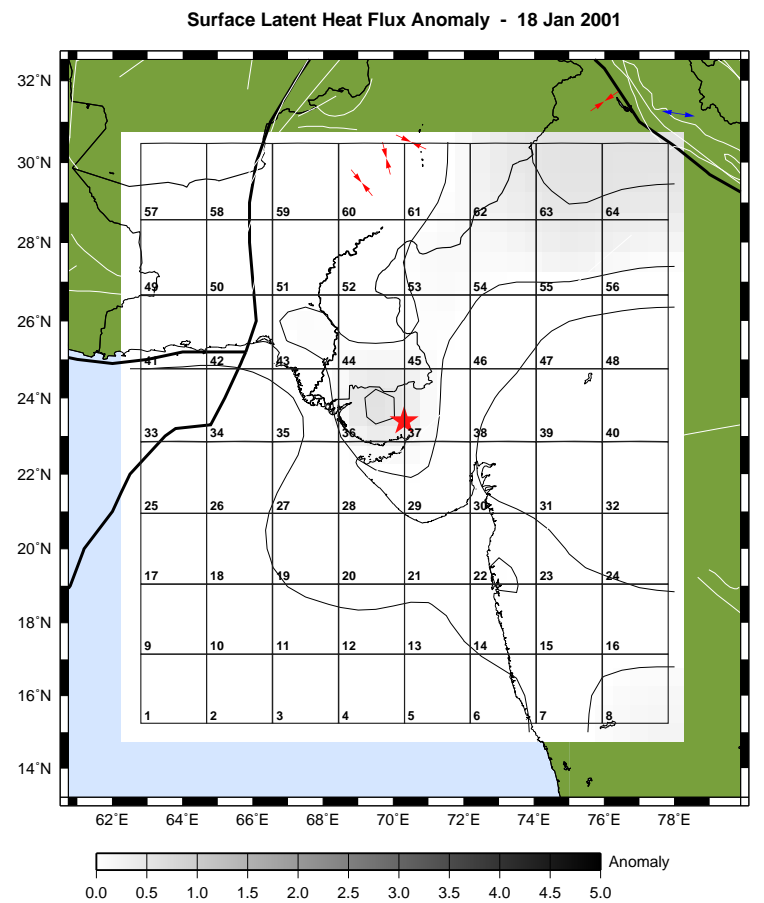

(c) SLHF anomaly for January 182001

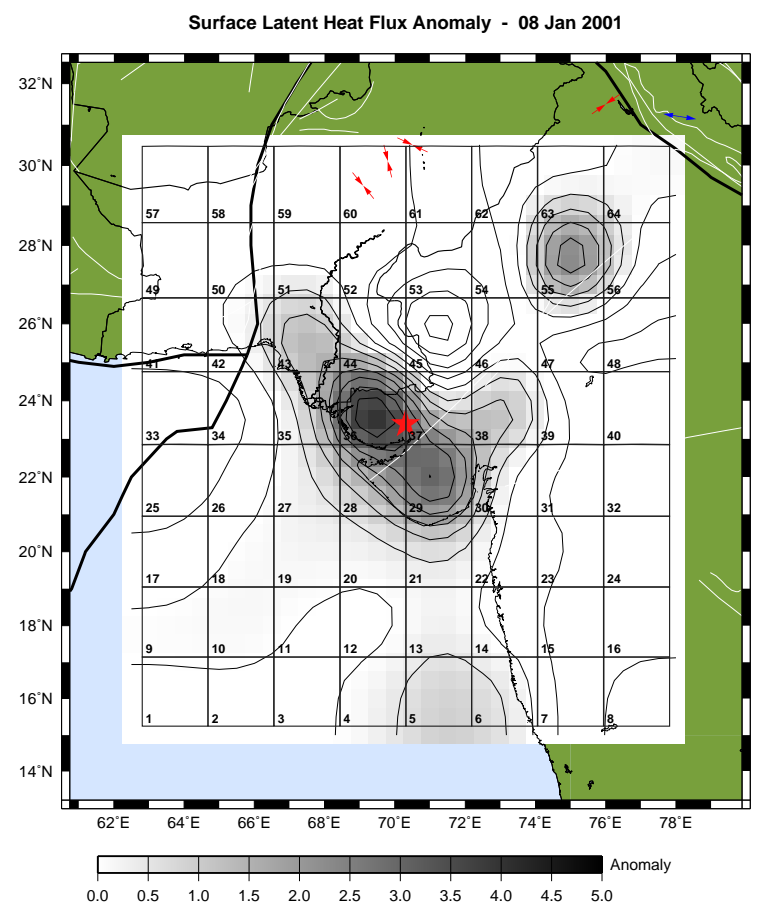

(b) SLHF anomaly for January 82001

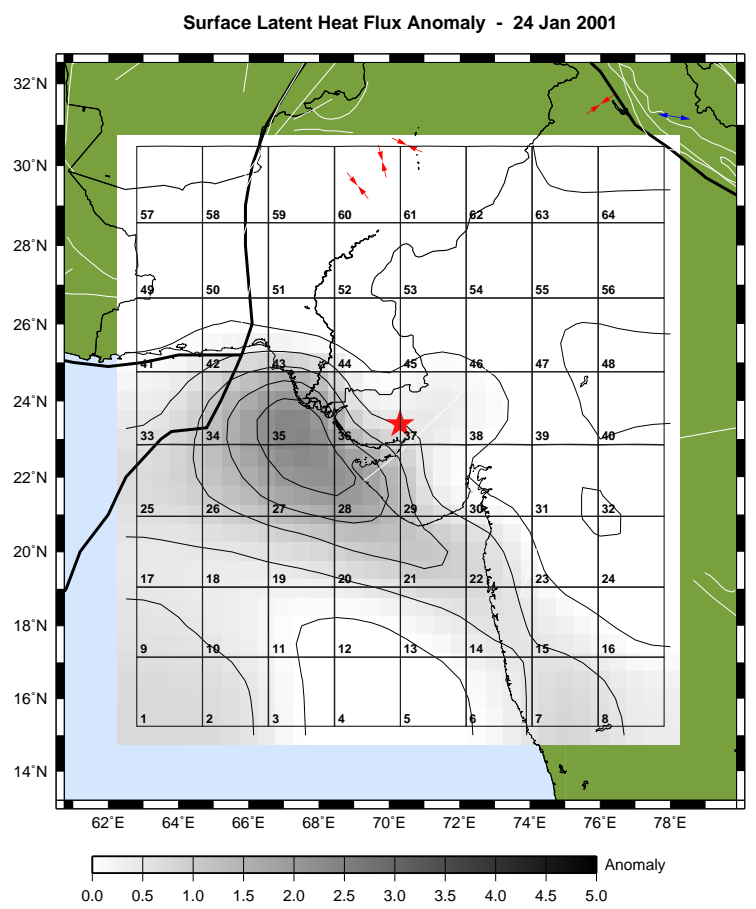

(d) SLHF anomaly for January 242001

Fig. 5. Sequence of SLHF anomalies for the Gujarat earthquake of 26 January 2001. 


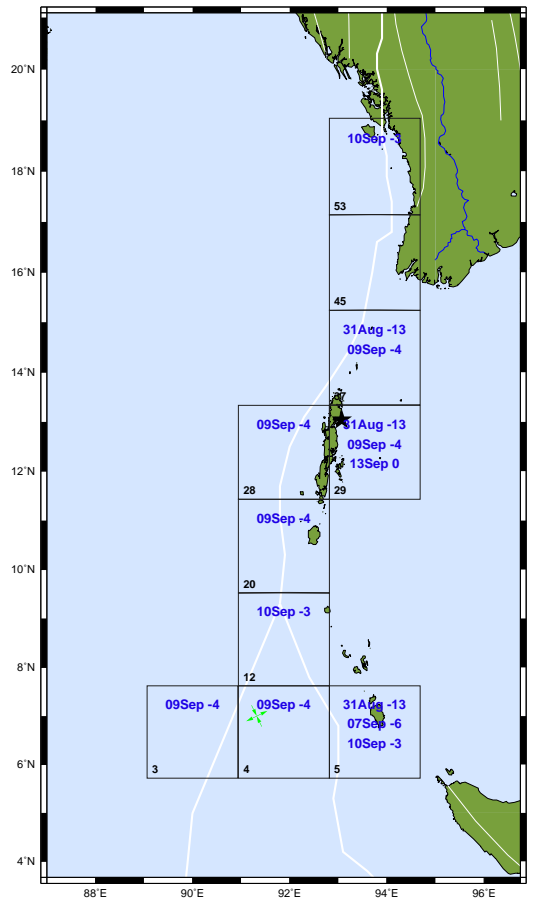

(a) Map of the region of the first Andaman Earthquake.

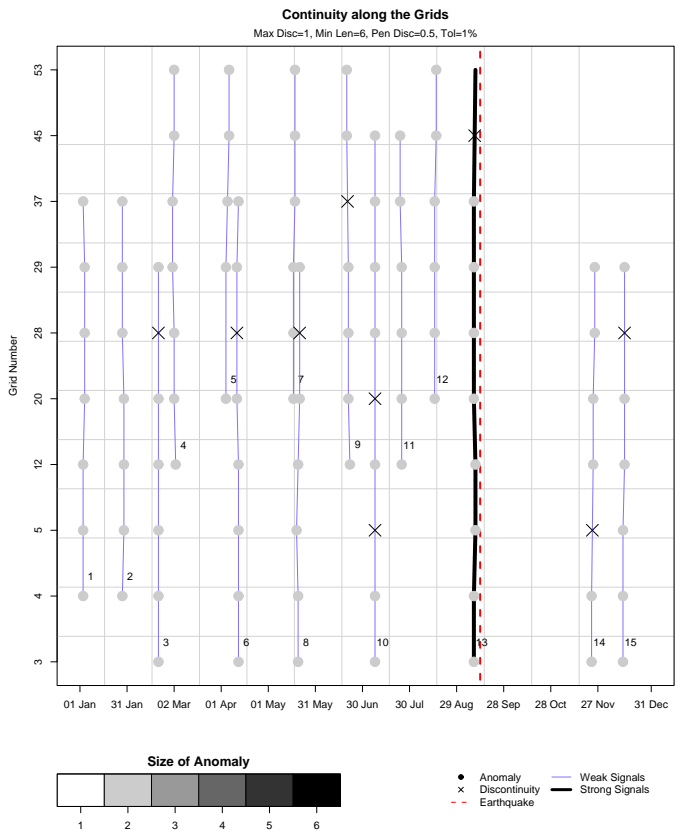

(c) Result of the time and space analysis for the first Andaman Earthquake.
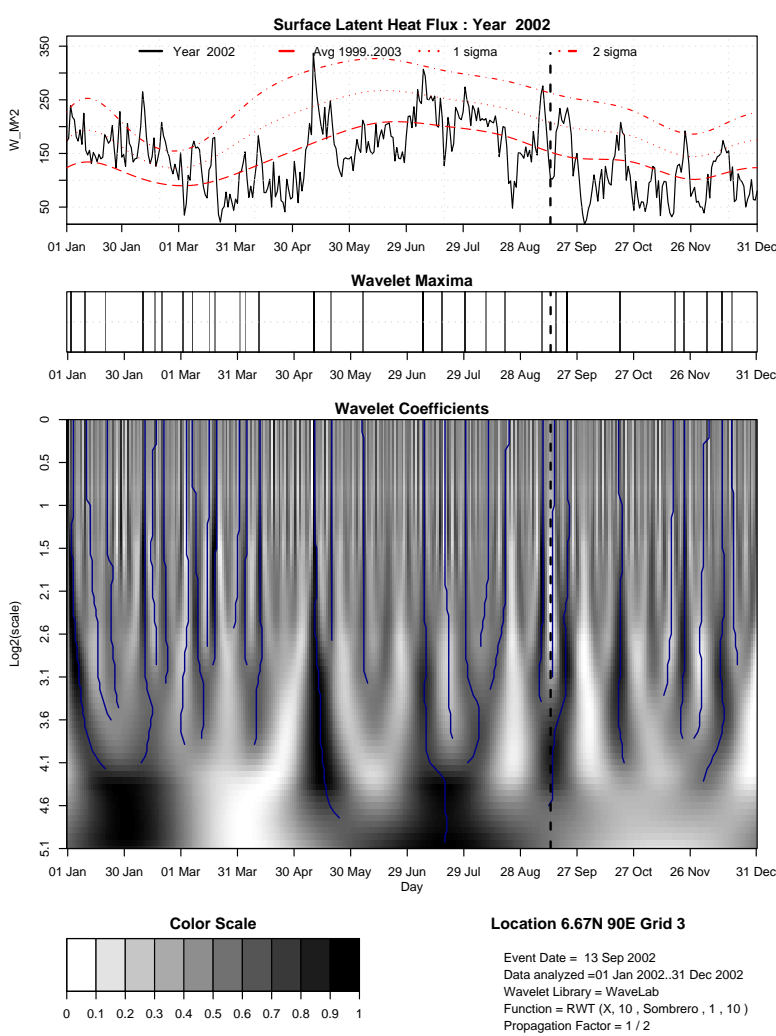

(b) Wavelet analysis for the fi rst Andaman Earthquake.

Fig. 6. Results for the Andaman earthquake of 13 September 2002. 


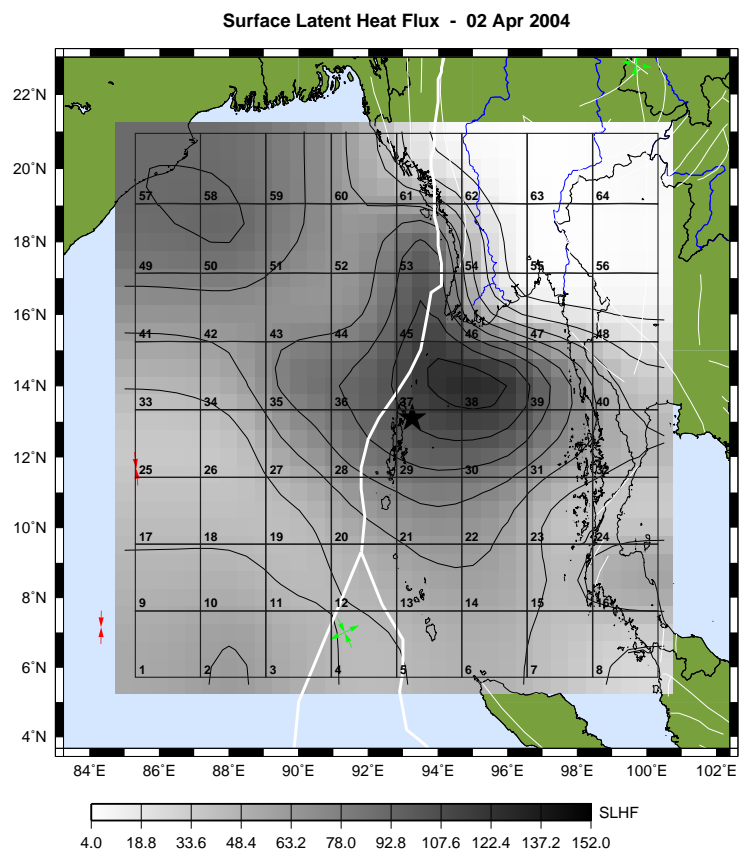

(a) Extent of the signal for the second Andaman Earthquake.
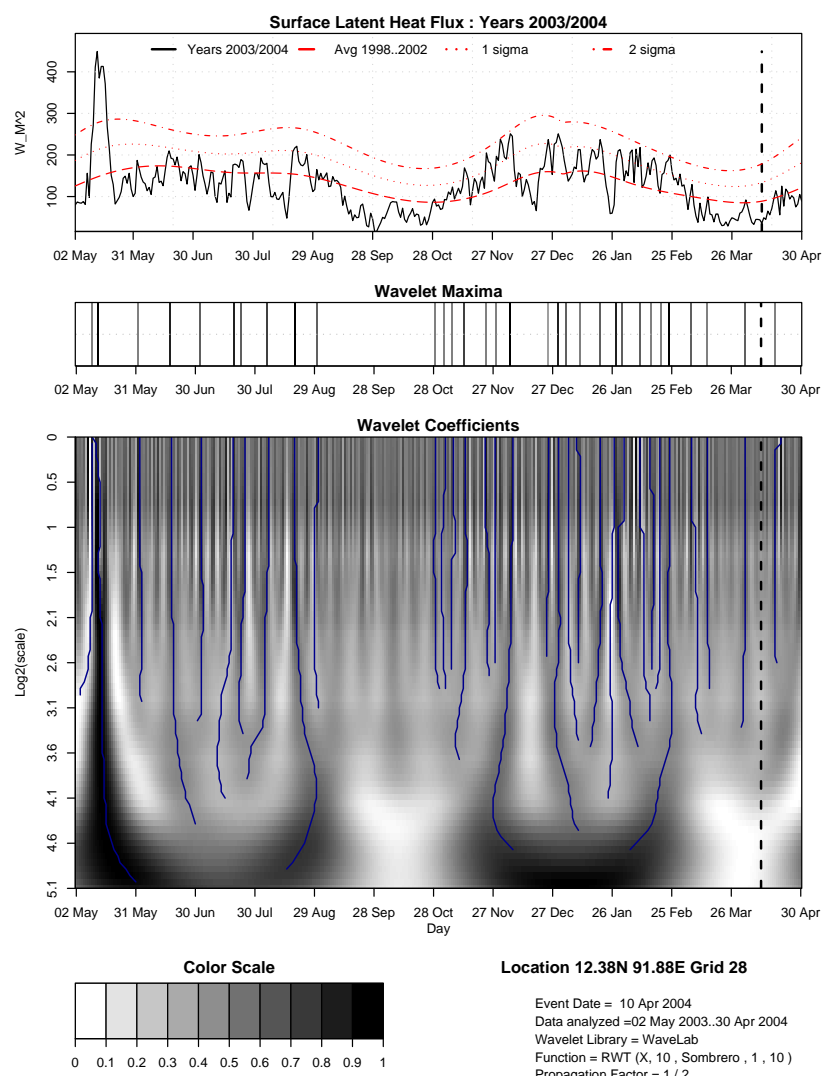

(b) Wavelet analysis for the second Andaman Earthquake.

Fig. 7. Results for the Andaman Earthquake of 10 April 2004.

The higher anomalies found are over the ocean and closer to the epicentral region.

\subsection{Andaman 1}

The first Andaman earthquake occurred on 13 September 2002 at 22:28 UTC, at location 13.04 N 93.07 E, with a focal depth of $21 \mathrm{~km}$ and magnitude 6.5 . This earthquake occurred on one of the most active seismic regions. The epicenter is lying within few kilometers of the continental boundary where the Indian plate meets the Eurasian plate. Numerous earthquakes and micro-earthquakes have been recorded since the last three years, Fig. 6a shows the grids considered for the analysis of SLHF. Unlike Gujarat, Pondicherry and Jabalpur earthquakes, whose epicenter were located away from the continental boundary, the Andaman island lies exactly over the continental boundary. The result of the wavelet analysis also shows the anomalous SLHF peak and the wavelet maxima curve associated with this earthquake event (Fig. 6b). The computation of the time and space continuity of the SLHF anomalies were chosen by selecting the grids lying exactly over the continental boundary. The maximum amount of stress occurs over the continental boundary, and this is the location where the largest anomaly was found. The results of the space and time continuity are shown in Fig. 6c. The results show that throughout one year period, there is only a single signal which propagates through all the chosen grids, and this occurs about 4 days prior to the earthquake event. The other anomalous signals do not propagate through the continental boundary. Other significant SLHF anomalies are seen about 12 days prior to the earthquake event, but such anomalies are found to be localized only over the epicentral region, and are not found to propagate throughout the continental boundaries. The other anomalies are not found to be associated with earthquake events due to their smaller extent, and smaller statistical significance. The selection of the grids related to this earthquake is found to be easier than in the case of the Gujarat earthquake, because the epicenter is in the proximity of the continental boundary. We emphasize that knowledge of the relevant geological structure and tectonics of the region is crucial for the selection of grid paths.

\subsection{Andaman 2}

The second Andaman earthquake occurred on 10 April 2004 at 14:05 UTC, at location 13.04 N 93.25 E, with a focal depth of $33 \mathrm{~km}$ and magnitude 5.4. This earthquake occurred extremely close to the epicenter of the earthquake of 13 September 2002. Although of much lesser intensity, this earthquake provides a good test case to study the shape and 


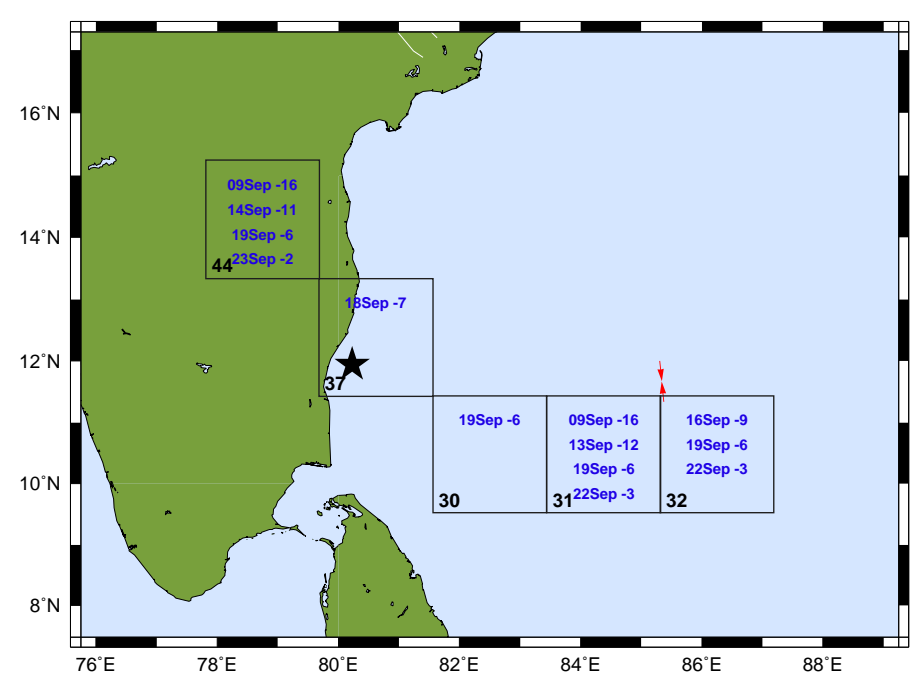

(a) Map of the region of the fi rst Pondicherry Earthquake.
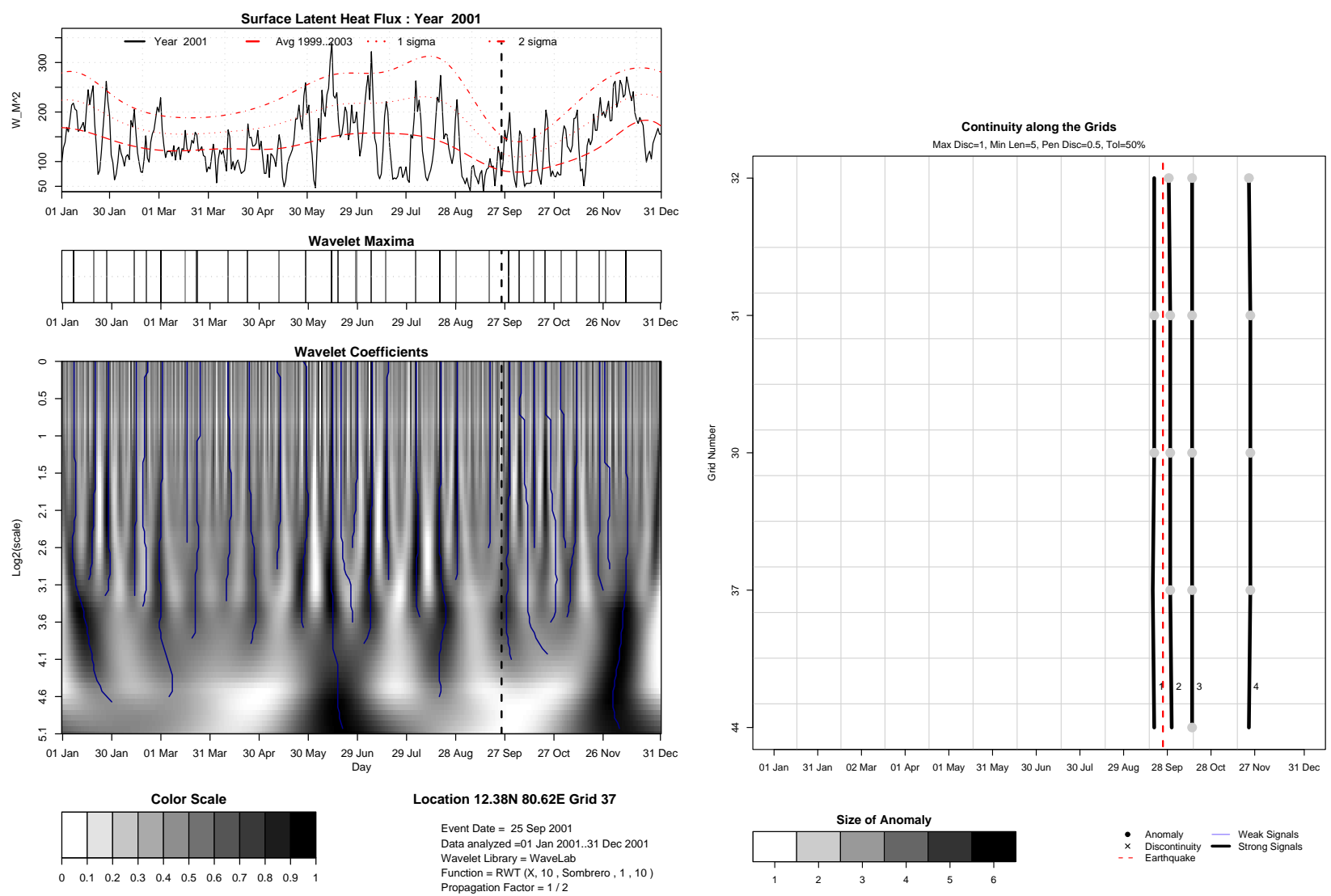

(b) Wavelet analysis for the Pondicherry Earthquake.

(c) Result of the time and space analysis for the Pondicherry Earthquake.

Fig. 8. Results for the Pondicherry earthquake of 25 September 2001. 


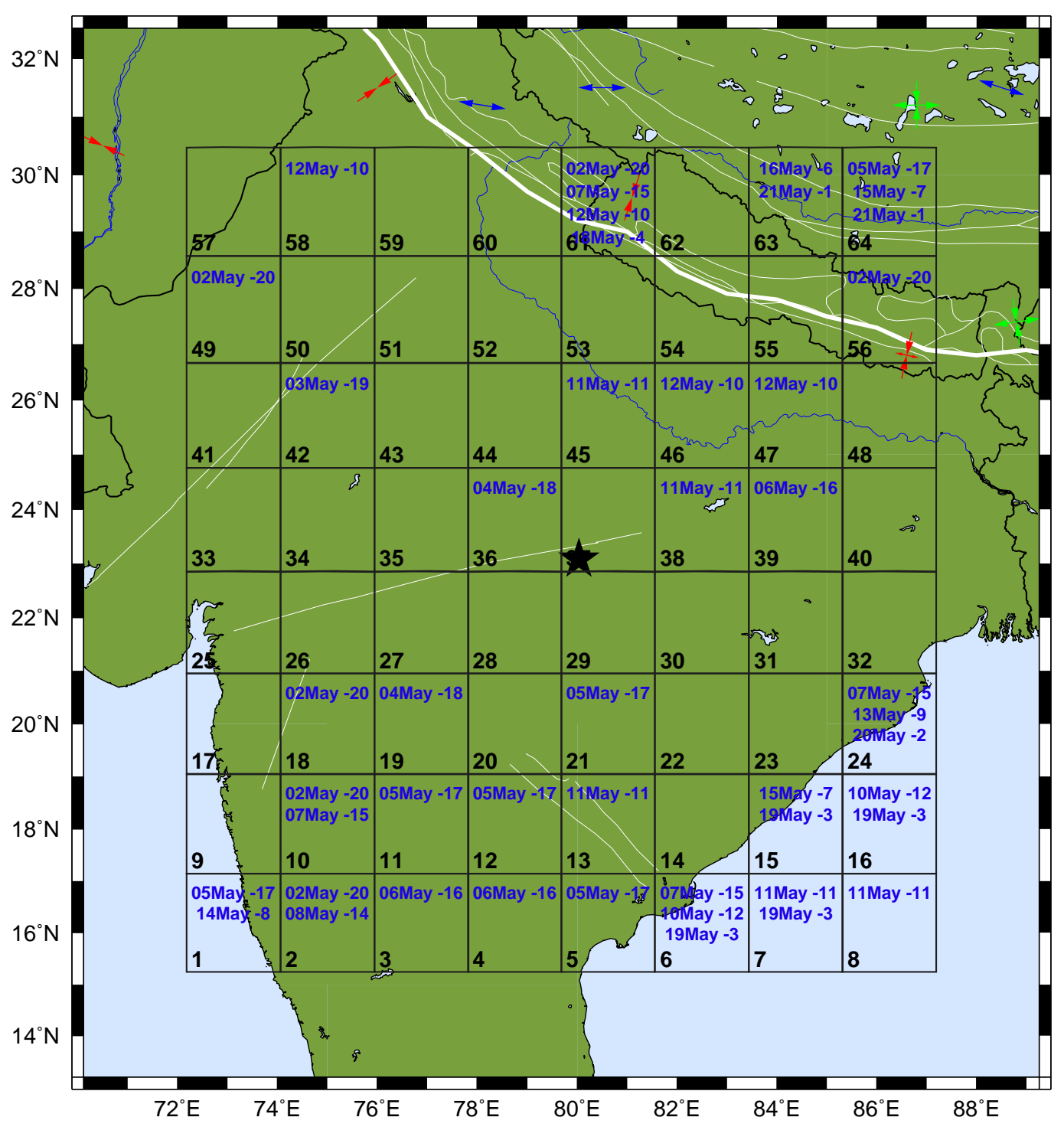

Fig. 9. Map of the region of the Jabalpur Earthquake of 22 May 1997. The grids used in the study are marked, labeled, and annotated with the date of the detected anomaly and the offset from the day of the earthquake. The epicenter is marked with a star.

the extent of the anomaly for this region. Figure 7 a shows the extent of the SLHF anomaly of this earthquake. The anomaly does not propagate through the continental boundary as observed for the other larger Andaman earthquake, but is more confined to the epicentral area. It is believed that the smaller extent of the SLHF anomaly is associated with the smaller intensity of the earthquake. The results of the wavelet analysis for the epicentral region shows the peak and the wavelet maxima curve associated with this earthquake event (Fig. 7b).

\subsection{Pondicherry}

The Pondicherry earthquake occurred on 25 September 2001 at 14:54 UTC, at location $11.94 \mathrm{~N} 80.22 \mathrm{E}$, with a focal depth of $19 \mathrm{~km}$ and magnitude 5.4. This earthquake also occurred far away from the continental boundary, but close to the ocean. A single prominent SLHF anomaly was detected about one week prior to the earthquake event that satisfies the space and time continuity requirements (Fig. 8a). Figure $8 \mathrm{~b}$ shows the results for the wavelet analysis for the epicentral region. The other signals which satisfy the space and time continuity are likely to be associated with aftershocks (Fig. 8c).

\subsection{Jabalpur}

The Jabalpur earthquake occurred on 22 May 1997 at 22.51 UTC, at location $23.08 \mathrm{~N} 80.04 \mathrm{E}$ with focal depth of $35 \mathrm{~km}$ and magnitude 6.0. This earthquake occurred in a region with very low seismicity, with the only other similar event recorded in 1938 in Satpura with magnitude 6.3. Analysis of SLHF data have been carried out over a large area of about $2000 \mathrm{~km}^{2}$ (Fig. 9). Since this earthquake occurred far away from the coast, no SLHF anomaly was found to 
be associated. It is believed that in the case of earthquakes occurring away from the ocean, the land-ocean-atmosphere coupling is not significant enough to provide anomalous changes in atmospheric parameters, and thus SLHF data do not provide characteristic anomalies which can be used as a precursor (Dey and Singh, 2003).

\section{Conclusion}

This paper presents an application of the study of SLHF anomalies associated with five recent Indian earthquakes. The methodology is based on temporal and spatial analysis of SLHF data to discriminate anomalies associated with earthquakes from other anomalies. The results presented in this paper show that prominent SLHF anomalies are found prior to Indian coastal earthquakes, which follow continuity both in space and time. Such SLHF anomalous peaks were not found in the case of the earthquake occurring far away from the coast (Jabalpur earthquake). The results presented here further validate the hypothesis that SLHF data contains precursory information only for coastal earthquakes, and set the basis for establishing a relationship between the magnitude and the extent of the SLHF anomaly and the magnitude of the earthquake.

Acknowledgements. This research was partially supported by NASA's office of Earth Science Enterprise under grant NAG1201009, NAG13-02054 and NAG13-03019, VAccess/MAGIC projects.

Edited by: M. Contadakis

Reviewed by: two referees

\section{References}

Cervone, G., Kafatos, M., Napoletani, D., and Singh, R. P.: Wavelet maxima curves associated with two recent Greek earthquakes, Nat. Haz. Earth Sys. Sci., 4, 359-374, 2004,

SRef-ID: 1684-9981/nhess/2004-4-359.

DeMets, C., Gordon, R., Argus, D., and Stein, S.: Current plate motions, Intern. J. Geophys., 101, 425-478, 1990.

Dey, S. and Singh, R. P.: Surface latent heat flux as an earthquake precursor, Nat. Haz. Earth Sys. Sci., 3, 749-755, 2003, SRef-ID: 1684-9981/nhess/2003-3-749.

Liu, J., Chuo, Y., Shan, S., Tsai, Y., Chen, Y., Pulinets, S., and $\mathrm{Yu}, \mathrm{S}$.: Pre-earthquake ionospheric anomalies registered by continuous gps tec measurements, Ann. Geophys., 22, 1585-1593, 2004,

SRef-ID: 1432-0576/ag/2004-22-1585

Maekawa, S. and Hayakawa, M.: A study on the association of ionospheric perturbations with the earthquakes in Japan, as based on the JG2AS signal observation at Moshiri (Hokkaido) and at Kamchatka (Russia), in: Geophys. Res. Abstr., Vol. 6, European Geosciences Union, 2004.

Miller, R. G., Miller, R., and Brown, B. W.: Beyond ANOVA: Basics of Applied Statistics, Chapman \& Hall/CRC, 1997.

Okada, Y., Mukai, S., and Singh, R.: Changes in atmospheric aerosol parameters after Gujarat earthquake of January 26, 2001, Adv. Space Res., 33, 254-258, 2004.

Ouzonov, D. and Freund, D.: Mid-infrared emission prior to strong earthquakes analyzed by remote sensing data, Adv. Space Res., 33, 268-273, 2004.

Pulinets, S. A. and Boyarchuk, K. A.: Ionospheric Precursors of Earthquakes, Springer Verlag, Berlin, 2004.

Qiang, Z.: Thermal infrared anomoly precursor of impending earthquakes, Pure Appl. Geophys., 149, 159-17, 1997.

Singh, R. P., Sahoo, A. K., Bhoi, S., Kumar, M. G., and Bhuiyan, C. S.: Ground deformation of the Gujarat earthquake of January 26, 2001, J. Geological Society of India, 58, 209-214, 2001.

Singh, R. P., Dey, S., Singh, V. P., Cervone, G., Sarkar, S., and Kafatos, M.: Prediction of coastal earthquakes using surface latent heat flux retrieved from satellite data, in: Proceedings of the World Congress on Natural Disaster Mitigation, Vol. 2, pp. 129 134, World Federation of Engineering Organisation, 2004.

Tramutoli, V., Bello, G. D., Pergola, N., and Piscitelli, S.: Robust satellite techniques for remote sensing of seismically active areas, Annali di Geofisica, 44, 295-312, 2001.

Tronin, A., Hayakawa, M., and Molchanov, O.: Thermal IR satellite data application for earthquake research in Japan and China, J. Geodynamics, 33, 519-534, 2002. 